Revue de l'Institut des langues et cultures

d'Europe, Amérique, Afrique, Asie et Australie

$41 \mid 2020$

Escrituras nómadas en el mundo hispánico contemporáneo

\title{
Roberto Bolaño: de la experimentación formal a la geografía axiológica
}

Roberto Bolaño: de l'expérimentation formelle à la géographie axiologique

Roberto Bolaño: from the Formal Experimentation to the Axiological Geography

\section{Santiago Guevara}

\section{OpenEdition}

\section{Journals}

Edición electrónica

URL: http://journals.openedition.org/ilcea/11277

DOI: 10.4000/ilcea. 11277

ISSN: 2101-0609

Editor

UGA Éditions/Université Grenoble Alpes

\section{Edición impresa}

ISBN: 978-2-37747-224-6

ISSN: 1639-6073

\section{Referencia electrónica}

Santiago Guevara, «Roberto Bolaño: de la experimentación formal a la geografía axiológica», ILCEA [En línea], 41 | 2020, Publicado el 03 noviembre 2020, consultado el 03 febrero 2021. URL: http:// journals.openedition.org/ilcea/11277; DOI: https://doi.org/10.4000/ilcea.11277

Este documento fue generado automáticamente el 3 febrero 2021

(C) ILCEA 


\title{
Roberto Bolaño: de la experimentación formal a la geografía axiológica
}

\author{
Roberto Bolaño : de l'expérimentation formelle à la géographie axiologique \\ Roberto Bolaño: from the Formal Experimentation to the Axiological Geography
}

\author{
Santiago Guevara
}

\section{Extraterritorialidad}

El escritor chileno Roberto Bolaño (1953-2003) se desvincula desde muy temprano de un territorio propio (léase patria o escuela literaria), en un vertiginoso afán de independencia. En efecto, la posición marginal del autor (hasta bien entrada su vida) actúa como rechazo a las escuelas literarias y a la tradición dominante. Este recorrido solitario, nómada y marginal encuentra sus raíces más profundas en la imagen que él mismo crea y que describe como La universidad desconocida (2007), una universidad elíptica, sin nombre ni dirección y por lo tanto desligada de cualquier tipo de institucionalidad. El autor presenta esta figuración abstracta como un espacio de libertad en el que él mismo se proyecta como un escritor libre y no deudor de nadie. Este deseo de demarcarse le permite entonces cuestionar e ironizar la relación del escritor con su contexto literario, cultural y político en profundidad:

El lector activo preconizado por Cortázar podía empezar la lectura con un patada en los testículos del autor y ver de inmediato en éste a un hombre de paja, un factótum al servicio de algún coronel de inteligencia, o tal vez de algún general con ínfulas de intelectual, lo que tampoco, tratándose de Chile, era muy raro, más bien lo raro hubiera sido lo contario, en Chile los militares se comportaban como escritores y los escritores, para no ser menos, se comportaban como militares, y los políticos (de todas las tendencias) se comportaban como escritores y como militares, y los diplomáticos se comportaban como querubines cretinos, y los médicos y abogados 
se comportaban como ladrones, y así hubiera podido seguir hasta la náusea, inasequible al desaliento. (Bolaño, 2004: 286)

2 En el imaginario del Bolaño la independencia de un escritor sólo es posible en la medida en que su relación con los hilos del poder se diluya. Dicha disolución implica una toma de distancia a través del exilio. En este sentido, la independencia sería radical y se expresa por el cuestionamiento permanente de la escritura pero también por una errancia permanente en el plano geográfico y mental. El extraterritorio desde el cual se posiciona el autor es identificable desde finales de los años 1970. En efecto, en La prosa de otoño en Gerona leemos otra clara alusión a la universidad desconocida: «Esta esperanza yo no la he buscado. Este pabellón silencioso de la universidad desconocida ${ }^{1}$.» La universidad desconocida no obedece entonces a un orden institucional y ni siquiera lógico-secuencial puesto que el autor «encuentra» algo que no estaba buscando. Años más tarde, en 2666 (2004) al referirse a la lectura que Hans Reiter hace de Wolfram Von Eschenbach leemos:

Wolfram, descubrió Hans, declara no poseer artes, pero no para ser tomado como un inculto, sino como una forma de decir que está liberado de la carga de los latines y que él es un caballero laico e independiente. Laico e independiente. (Bolaño, 2004: 104)

3 «Independencia», «laicismo» y «honradez», además de ser palabras recurrentes en la obra del autor, sugieren un marco de valores «indispensables» a la escritura. En el discurso pronunciado en el otorgamiento del premio Rómulo Gallegos y al referirse al hecho que no conocía previamente a ninguno de los jurados, el autor expresó: «Mi única riqueza es $\mathrm{mi}$ honra ${ }^{2} . »$ (Manzoni, 2002: 13) Constatamos que la extraterritorialidad de la obra del autor no corresponde únicamente al abandono de un territorio geográfico sino con mayor importancia, a la búsqueda de un territorio axiológico.

4 A su turno, la búsqueda incesante de extraterritorialidad en Bolaño es más claramente identificable en su identidad. Las nacionalidades chilena y española lo ubican en un territorio intermedio y por lo mismo inestable. Al poseer una identidad híbrida, Bolaño se permite escribir desde un punto de vista no institucional. Tal como Harel (2005) lo señala, la identidad híbrida de un escritor produce que las nociones de identidad nacional y de literatura nacional disminuyan sustancialmente en su imaginario. Es de esta manera que Bolaño parece acercarse al carácter laico e independiente que preconiza y que se respira en el trasfondo de su obra. No obstante, este extraterritorio pude ser más claramente caracterizado a través del descentramiento de su narrativa.

\section{Intertextualidad}

5 La casi totalidad de la obra de Bolaño comprende libros de extensión breve con excepción de 2666, el cual está compuesto por cinco novelas que no superan las 250 páginas cada una. La extensión lograda en 2666 se realiza entonces a través de un fenómeno narrativo de ampliación, sea de un tema sea de un personaje en otro texto más amplio. Así, por medio de una estructura de rizoma, una novela puede contener otras o de un tema se puede desprender un nuevo relato creando textos ilimitados en los que el desplazamiento toma el lugar central, tal como lo señala Manzoni (2002). Esta proyección cartográfica de los relatos permite la postulación de una narrativa en continuo movimiento tanto a nivel intratextual como intertextual. 
El aspecto intertextual más evidente es la presencia del narrador Arturo Belano, alter ego de Bolaño, enunciado en diversos textos como B, Belano, o más explícitamente como Bolaño. Este personaje encarna la imagen de un escritor latinoamericano, nómada y miserable que articula su vida alrededor de la literatura y cuyo ethos corresponde a los valores anunciados anteriormente (independencia, honradez, laicismo, etc.). Este personaje alter ego forma parte central del mapa conceptual (Sánchez, 2012) que guía su obra puesto que se entrelaza constantemente con otros personajes, con otros motivos y en otras estructuras narrativas logrando insertarse en la duración y ambiciones del proyecto narrativo del autor pero también en el imaginario del lector quien le sigue la pista en sus deambulaciones. Otro aspecto intertextual de la obra bolañeana es que los temas funcionan como fragmentos desarticulables, y a lo largo de su reescritura, llegan a ser motivos recurrentes. Es así como la intertextualidad es prospectiva: un libro anuncia el libro siguiente o lo amplia. El título mismo de 2666 ya se había enunciado en Amuleto (1999) en el pasaje en que Auxilio Lacouture sigue a Arturo Belano y Ernesto San Epifanio por la ciudad de México:

[...] la Guerrero, a esa hora, se parece sobre todas las cosas a un cementerio, pero no a un cementerio de 1974 [...] sino a un cementerio de 2666 , un cementerio olvidado debajo de un párpado muerto o nonato. (Bolaño, 1999: 76)

Constatamos igualmente que el título de cada una de las novelas que componen 2666: $\mathrm{La}$ parte de... La parte de... La parte de... La parte de... La parte de... crean pasarelas intertextuales. Los sujetos y temas marginales de una historia pasan a ser centrales en otras, como se puede comprobar en 2666. No obstante, el ascenso de un personaje marginal al centro narrativo implica un desplazamiento del punto de vista de la historia contada puesto que al reescribirse la historia, se reescribe con un foco diferente. De manera inversa, un motivo central deja de serlo en un nuevo texto, desalentado al lector en su deseo de jerarquización temática. Este desplazamiento representa un desafío para el lector quien se ve atrapado en el juego de desvirtuar lo que parecía esencial en el relato y también un desafío para el autor quien debe mantener en equilibrio lo central con lo periférico y lo micro con lo macro. En esta lógica, la novela es un texto íntegro en el sentido de confluencia narrativa, debido a que cada segmento desplazado es generador de otra unidad independiente de significado.

8 Por lo demás, la movilidad de los personajes en 2666 construye el hilo conductor del diálogo intertextual entre las diferentes partes de la novela. En este punto entendemos la idea primera de Bolaño de publicar las cinco novelas que componen 2666 separadamente con un año de diferencia la una de las otras, en una suerte de novela por entregas: La parte de los críticos anticipa a Amalfitano, La parte de Amalfitano anticipa a Fate, $L a$ parte de Fate anticipa los crímenes y La parte de los crímenes anticipa a Archimboldi. De esta manera, la intertextualidad genera un nuevo modelo estructural. Por ejemplo, de La literatura nazi en América (1996b) [un inventario de biografías apócrifas] nace Estrella distante (1996a) una novela un tanto más clásica en su construcción. De la misma manera el tema de la infamia en la primera pasa a ser el del horror en la segunda.

9 En 2666 cada novela puede ser vista como un modelo estructural autónomo, a saber: $L a$ parte de los críticos como un viaje iniciático por la literatura, La parte de Amalfitano como la novela del exilio, La parte de Fate, como la búsqueda de un destino, La parte de los crímenes, como los inventarios del horror y La parte de Archimboldi como una historiografía de la literatura. En esta lógica, 2666 establece una red impresionante de 
conexiones intratextuales y extratextuales (Macaya, 2009) en donde los personajes se cruzan en espacios reales reconocibles: México, Alemania, España, Francia, Italia, e incluso África, o en espacios simbólicos como la criminalidad, el horror o la infamia. El juego permanente entre centro/periferia se ve más claramente en el siguiente fragmento:

De los cuatro Morini fue el primero en leer, por aquellas mismas fechas, una noticia sobre los asesinatos de Sonora, aparecida en Il Manifesto y firmada por una periodista italiana que había ido a México a escribir sobre la guerrilla zapatista. La noticia le pareció horrible. En Italia también había asesinos en serie, peor rara vez superaban la cifra de diez víctimas, mientras que en Sonora las cifras sobrepasaban con largueza las cien. (Bolaño, 2004: 64)

10 En este fragmento el conocimiento de los crímenes se presenta de manera periférica y tangencial y así mismo se pierde. Morini no piensa ni se interesa por los crímenes sino por la periodista y su personalidad: «Me enamoraría de ella hasta la muerte, pensó. Una hora después ya había olvidado por completo el asunto.» (Bolaño, 2004: 64) En efecto, cada punto de contacto entre las novelas se expande en otras a través de una historia que no imaginábamos y que va a proyectar a su vez otros puntos de contacto periféricos que serán a su vez desarrollados y así sucesivamente. Este recurso le permite a Bolaño moverse con soltura en la extensión de la novela y sobre todo hacer que los personajes de su obra se intersecten a través de microhistorias a la manera del rizoma tal como lo entiende Deleuze (1980). Cada novela que compone 2666 narra la misma historia pero desde otro punto de vista, como si cada uno de los relatos contuviera la novela misma y aún más como si cada micro relato también contuviera la historia misma. Según Montané (2010), la figura móvil del personaje alter ego sumado a la intertextualidad hacen que la obra de Bolaño sea vista como una estructura narrativa móvil, encajando perfectamente con la idea que el público lector puede hacerse de una literatura nómada: rica en espacios, tiempos, posibilidades y sobre todo rica en libertad. A la desarticulación del centro enunciativo, sea geográfico o axiológico se suma un proceso de desterritorialización que completa la postulación de una obra extraterritorial.

\section{Desterritorialización}

11 Tal como lo enuncia Deleuze (1996) el movimiento recíproco de conquista y abandono, de entrada y salida en un territorio narratológico y genérico refleja un proceso de llegar a ser ininterrumpido. En este proceso los motivos de una novela potencian el simbolismo de una imagen determinada. En la obra de Bolaño reconocemos claramente la figura de la mujer solitaria como pista paratextual y narrativa. En esta conquista de un nuevo territorio literario se amalgaman el lenguaje y la imagen poética. Dicha síntesis de tipo poético logra cristalizarse en imágenes de fuerza descomunal, tales como el desierto o la muchacha solitaria (Guevara, 2013: 55-66).

Por una parte, el posicionamiento de la imagen poética dentro de la prosa llega a crear pequeños fragmentos autónomos que bien podrían leerse como poemas. Por otra parte, la desterritorialización del género pasa por un tratamiento particular del lenguaje y de la enunciación narrativa. En el caso de Los detectives salvajes el rasgo distintivo de la enunciación es la polifonía textual y es a través de ésta cómo los personajes son aprehendidos desde una mirada oblicua. A su turno, en 2666 la aprehensión de la realidad es caleidoscópica pero se consigue por medio de una enunciación totalizante en lugar de polifónica. Así, si en Los detectives salvajes leemos una novedosa apuesta 
narrativa, en 2666 vemos una estructuración más clásica de cada uno de los elementos narrativos de las cinco novelas que la componen. La voz narrativa de 2666 es única y totalizante; una tercera persona en lugar de una primera como es acostumbrado en Bolaño. Sin embargo, esta voz única y totalizante de un narrador omnisciente, pronto se refleja llena de vacíos, de dudas, y sobre todo afronta el problema de lo que considera como indescriptible e inenarrable. Este síntoma de una voz que no logra conocer más de lo que nosotros mismos como lectores conocemos acerca de la trama de la historia, se desborda en una prosa amena y legible, pero a la vez llena de vacíos que interpelan al lector. Además, la carencia de la información (o la negativa del narrador a revelarla) hace que esa voz asuma una tonalidad poética que intenta narrar a través de la creación de imágenes. Esta voz totalizante rompe entonces con los principios de la voz narrativa decimonónica-omnisciente al instalar un clima de desconfianza permanente en el lector y en el texto mismo:

Llegados a este punto es necesario aclarar algo para el buen (o mal) entendimiento del texto. Es verdad que hubo una reserva a nombre de Benno Von Archimboldi. Sin embargo esa reserva no llegó a concretarse y a la hora de la salida no apareció ningún Benno Von Archimboldi en el aeropuerto. (Bolaño, 2004: 80)

13 La enunciación encarnada en la voz narrativa omnisciente reconoce la dificultad de narrar y se confiesa llena de dudas ante el lector. La desconfianza que la literatura de Bolaño instaura, proviene de la voz narrativa como fuente primaria de la duda y como resultado de un proceso de desterritorialización de la misma. La falsa unidad de la voz narrativa abre espacios fragmentados a diferentes voces y por lo tanto a diversos discursos tal como lo señala Manzoni:

Esta es una escritura que violenta la unicidad. Bolaño parece escribir fragmentos de un texto único, del cual conocemos sólo pedazos. El juego es: el fragmento que pervierte la obra, que la desecha como totalidad, también la desea. (2005: 126)

En la obra de Bolaño, la desterritorialización del lenguaje, de las voces narrativas y de los personajes mantiene una relación triangular en la que el lector debe desplazar su centro temático, temporal o espacial constantemente. En esa lógica de entrada-salida, el lector es llevado de la mano hasta el umbral del horror donde ni siquiera los personajes se atreven a entrar. Ilustrativamente corroboramos que en 2666, ni los críticos, ni Amalfitano, ni Fate osan entrar de lleno en el misterio de los crímenes. La experiencia literaria del horror entra entonces en los dominios de lo innenarrable. Al respecto Bolaño en su discurso de recepción del premio Rómulo Gallegos dijo:

Entonces ¿qué es una escritura de calidad? Pues lo que siempre ha sido: saber meter la cabeza en lo oscuro, saber saltar al vacío, saber que la literatura es básicamente un oficio peligroso. (Manzoni, 2002: 215)

15 Como Deleuze (1980) lo afirma, desterritorializar produce una forma de desencanto. En el caso de Bolaño el desencanto de la literatura llega a ser un tópico en toda su obra. La voz narrativa abandona el territorio de las certezas para entrar en zonas oscuras materializadas por la dificultad de narrar, como si los narradores dieran palos de ciego tratando de atinar a una realidad indefinible y huidiza. Palabras como inefable, inenarrable, agrafía, incomunicable, indefinible, inaprensible, son ilustrativas en su obra porque más que expresar una carencia, según Manzoni (2002), denotan la difícil tarea de trasponer/yuxtaponer la realidad en el lenguaje. Si el lenguaje es inaprehensible en el imaginario del autor, lo único que queda a sus narradores es un sentimiento de impotencia y desde luego, la posibilidad de volver a narrar la misma historia de otra manera. La falta de certezas, la inestabilidad narrativa y la desconfianza frente al 
lenguaje producen un efecto seductor en el lector que ve en estas características la representación formal de la libertad que el nomadismo sugiere. En esta lógica, la obra de Bolaño representa el lugar en que confluyen la intertextualidad y la creación de un universo de motivos, formas y valores que responden a la concepción de la literatura del propio autor pero también a las expectativas implícitas de los lectores, que ven en ella, el símbolo de la libertad y de la independencia literaria.

\section{Del nomadismo a la proyección axiológica}

Los elementos de extraterritorialidad, intertextualidad y desterritorialización que hemos enunciado no pueden ser vistos únicamente como las bases de una literatura nómada. En efecto, a través de su postulación en la obra de Bolaño, éstos pueden darnos indicios de todo un marco de valores que determina su literatura tal como lo sugiere Andrea Cobas:

Muchos de los poetas representados en las narraciones de Bolaño revelan una ética diferenciada que escapa del perímetro habilitado por el mercado cultural. Como en los años 70 la errancia, el fracaso y la marginalidad son marcas que identifican a aquellos poetas decididos a vivir la poesía. (2008: 2)

Constatamos que la mayoría de los personajes de Bolaño son latinoamericanos exiliados e inmersos en dinámicas nómadas / errantes e incrustados en un contexto históricodemográfico bien definido que correspondería al exilio de latinoamericanos (especialmente hacia Europa) durante las últimas tres décadas del siglo xx. Existe entonces una dinámica constante en los personajes de Bolaño: del exilio se desprende la errancia y el nomadismo y con relevancia la marginalidad que ya hemos evocado. Esta dinámica general de la obra concierne de manera particular a los personajes en su sensibilidad. Así, el personaje (por lo general un poeta) exiliado, errante, marginal y ubicado en un extraterritorio se considera como poseedor de una suerte de iluminación que expresa a través de un sentimiento de incomprensión frente al desprecio del cual es víctima durante su recorrido nómada. Su movimiento constante, su inestabilidad geográfica, su conquista y abandono del territorio hacen que su vida oscile entre el menosprecio que sufre y el reconocimiento al cual aspira como lo vemos en el caso del personaje Gasparín en La pista de hielo; una suerte de santo en medio de un mundo depravado. Dicha oscilación que también representa un nomadismo interior, hace surgir el sentimiento de incomprensión y una perdida efectiva de estatus en la jerarquía social y por consiguiente una pérdida de dignidad. En Amberes (2002) podemos leer: «El escritor es un tipo sucio con las mangas de la camisa arremangadas y el pelo corto mojado en transpiración acarreando tambores de basura.» (Bolaño, 2002: 71) El personaje-escritor en este caso es un exiliado errante e incomprendido de cual la gente no alcanza a apreciar su grandeza, puesto que sus condiciones actuales (sucio y recolector de basura) esconden su verdadera pureza e incorruptibilidad. Lo que resulta interesante en este caso es que la incomprensión de la cual parece ser víctima el personaje, llega a ser para él una promesa de redención venidera, haciéndonos entrar en la figuración formal y axiológica del acto nómada.

Así, el heroísmo y la incorruptibilidad se consolidan como los valores más sólidos de los personajes nómadas y de manera curiosa, el heroísmo de los personajes no está asociado a la idea romántica de una misión personal fundamental sino más bien al valor de la incorruptibilidad. El caso de un personaje recurrente en la obra (el personaje- 
poeta) puede ser ilustrativo. A lo largo de su errancia Gasparín en La pista de hielo, se define por su pureza de espíritu que luego se transforma en marginalidad para desembocar en la ejecución de actos heroicos y en acciones incorruptibles, mostrando el carácter fundamental de este último valor en el seno del recorrido nómada de los personajes. De esta manera, todo movimiento, vagabundaje o errancia va acompañado de un marco de valores propio al autor y que podríamos llamar una geografía axiológica, únicamente posible a través de prácticas formales como la intertextualidad. La obra de Bolaño comporta un sistema de vasos comunicantes que permiten que la noción de literatura nómada circule en permanencia. Si tomamos Amberes escrita hacia 1980, La pista de hielo escrita hacia 1990 y Estrella distante escrita en 1996, comprobamos que responden a una lógica iniciática, en primer lugar temporal, luego espacial y finalmente axiológica. Separadas por 10 años en su redacción, las tres obras se comunican constantemente por medio de la aparición del personaje-poeta y de su errancia. La forma misma de los textos hace explicita la comunicación y evolución. En Amberes, etapa inicial del nomadismo del personaje, la forma es discontinua y el discurso completamente fragmentado apelando a la extraterritorialidad en la cual los espacios y tiempos se multiplican casi de manera incoherente. En La pista de hielo, etapa intermedia, las voces narrativas se descomponen en tres relatos diferentes pero que cuentan la misma historia a través de una focalización cada vez diferente (Fisbach, 2010). Estrella distante, etapa final de la errancia del personaje-poeta está organizada en secuencias equilibradas en las cuales una única voz narrativa cuenta la historia. El tiempo presente de indicativo en Amberes (tiempo verbal privilegiado para la creación de imágenes, y la representación de espacios, tiempos o aventuras aun no vividas por el joven personaje-poeta), aparece en La pista de hielo en alternancia con el pretérito indefinido (tiempo verbal usual para evocar acciones irreversibles, un recorrido terminado que se revive con fuerza como si volviera a ser de actualidad). Finalmente, en Estrella distante, el tiempo verbal privilegiado es el pretérito imperfecto (tiempo que hace desfilar un pasado terminado y que ya no volverá nunca). Así, comprobamos que la evolución del recorrido nómada del personaje-poeta y su marco de valores se definen por el tiempo verbal y por la composición formal de cada uno de los relatos. El proceso de desterritorialización o de «llegar a ser» ininterrumpido del personaje-poeta alcanza su expresión máxima en Estrella distante. En efecto, el personaje-poeta de esta novela, se sitúa en el momento en el que su errancia ha sido completa: el personaje-poeta ya ha conocido la dictadura militar chilena (1973), el exilio en América central y posteriormente en Europa, los amores perdidos, el fracaso de su carrera literaria, la soledad, la pobreza, la amargura, el menosprecio, la incomprensión y en general, todos los estados que componen el imaginario del nomadismo en Bolaño (Duran-Merk, 2010). El narrador de Estrella distante, como el joven poeta de Amberes está solo; está enfermo, esta roído por la amargura y el sentimiento de fracaso, casi no publica nada y sin embargo se permite expresar: «Le dije que para mí Carlos Wieder era un criminal, no un poeta.» (Bolaño, 1996: 126) refiriéndose al caso del asesino Wieder quien justificaba sus crímenes bajo el estandarte de «actos artísticos». Esta frase funciona como una prueba irrefutable del espíritu incorruptible del narrador en el contexto de la catástrofe ética y moral que representó la dictadura militar chilena. En Amberes, 20 años antes, este rasgo distintivo era exactamente el mismo, salvo que expresado así: «Sótano cuya única virtud es la limpieza» (Bolaño, 2002: 55) en referencia a la ética del joven poeta. Dicha virtud que, inicialmente, sólo estaba enunciada, es puesta en práctica en una situación concreta en Estrella distante. El marco de valores y la ética del 
personaje-poeta en la obra de Bolaño, se definen entonces en función del movimiento de la narrativa a nivel formal; extraterritorialización, intertextualidad, desterritorialización pero también a nivel de la diégesis; iniciación de los personajes, pruebas, errancia. Podemos afirmar que el personaje-poeta de Estrella distante logra a través de dicha frase afirmarse e introducirse en un espacio simbólico de libertad, de integridad a prueba de todo. Podemos afirmar que la proyección axiológica en la obra de Bolaño no está fija sino en continuo movimiento en coherencia con un ambicioso proyecto literario.

19 Si bien los valores como la incorruptibilidad, el heroísmo y la libertad resultan del carácter nómada de la literatura del autor, éstos parecen también formar parte de la construcción del término «bolañista» que hace referencia al hecho de ser partidario de la obra del autor. En este caso, este significante se integra en una polisemia más amplia que el simple hecho de apreciar la literatura del autor, para enunciar simbólicamente las relaciones del individuo con el mundo y por ende el marco de valores que la obra postula. En dicha lógica, ser «bolañista» se traduce por una manera de ser, de ver el mundo, de comportarse y de asumir la vida. El significado sugerido del significante «bolañista» apela constantemente a los valores nómadas de la obra: la valentía, la voluntad, el movimiento, la fragmentación y la inestabilidad entre otros. El significante «bolañista» puede igualmente ser considerado como un símbolo más que como un emblema o una alegoría debido a su modo de significación, que consiste en estar cargado de una mezcla afectiva y dinámica (Chevalier, 1982) que nos reenvía a una estructura de tipo intertextual en donde la conquista y el abandono del territorio constituyen sus principales características.

\section{Conclusiones}

La obra de Roberto Bolaño en general y 2666 en particular territorializan/ desterritorializan nuevos espacios genéricos y temáticos. Su producción literaria se articula alrededor de conceptos de ruptura como el devenir de los personajes, las líneas de fuga que cada tema proyecta, la estructura de rizoma que sostiene la estructura y las cartografías que sirven al lector de código topográfico. Los desplazamientos intratextuales y extratextuales de los diferentes personajes en la obra de Roberto Bolaño nos dan cuenta de un nomadismo permanente (Sánchez, 2012) y aún más, de una obra en movimiento. Dos procesos narrativos dan cuenta de este fenómeno de extraterritorialidad. En primer lugar, la desarticulación del centro enunciativo que conduce a una amplia red intertextual dentro de su obra. En segundo lugar la desterritorialización genérica que produce una síntesis narrativa (poesía-prosa) y una triangularidad enunciativa (personajes-voces narrativas-lenguaje). La obra de Bolaño, que podemos calificar de nómada, es un proyecto directamente ligado al deambular y al errar. A nivel intratextual se destaca un personaje arquetípico: el poeta exiliado latino americano que lleva una vida nómada y llena de aventuras a lo largo de los textos (Espinosa, 2010). A nivel intertextual subrayamos la construcción literaria de un extraterritorio. Así, en su obra, el errar no es solamente geográfico sino también literario como lo comprueba su idea de la Universidad desconocida. De hecho, la compleja intertextualidad de su obra obedece a un principio creador de movimiento pero también a la postulación de toda una geografía axiológica cuyo centro es la incorruptibilidad y el heroísmo. 
21 Roberto Bolaño convierte el nomadismo clásico en una búsqueda literaria que potencia una serie de rasgos nómadas: marginalidad, pobreza, aventura, incertidumbre, provocación, heroísmo y desconfianza entre otros. Podemos entonces afirmar que a través de la creación de un territorio literario nómada, el autor transforma el acto de errar en actos dirigidos por un marco de valores propio. Más aún, la obra del autor muestra bien que ésta responde con suficiencia, como lo enuncia Harel (2005) a los valores implícitos en la noción de nomadismo, a saber: aventura, libertad, independencia, inestabilidad, movimiento y peligro. Por último y en toda justicia, no podemos más que reconocer en la geografía axiológica de Bolaño, los ecos lejanos pero plausibles de una estética romántica reactualizada.

\section{BIBLIOGRAFÍA}

BENMILOUD Karim (2007), Les astres noirs de Roberto Bolaño, Bordeaux: Presses universitaires de Bordeaux.

BOLAÑo Roberto (1996a), Estrella distante, Barcelona: Anagrama.

BOLAÑo Roberto (1996b), Literatura nazi en América, Barcelona: Anagrama.

BOLAÑo Roberto (1998), Los detectives salvajes, Barcelona: Anagrama.

BOLAÑo Roberto (1999), Amuleto, Barcelona: Anagrama.

BOLAÑo Roberto (2000), Tres, Barcelona: Acantilado.

BOLAÑo Roberto (2002), Amberes, Barcelona: Anagrama.

BOLAÑo Roberto (2004), 2666, Barcelona: Anagrama.

BOLAÑo Roberto (2007), La universidad desconocida, Barcelona: Anagrama.

BOLAÑo Roberto (2009), La pista de hielo, Barcelona: Anagrama.

CHEVALIER Jean \& DGHEERBRANT Alain (1982), Dictionnaire des symboles : mythes, rêves, coutumes, gestes, formes, figures, couleurs, nombres, Paris : Laffont.

COBAS Andrea (2008), «Marginalidad y derrota: la poesía infrarealista de Roberto Bolaño», en línea en Academia: <https://www.academia.edu/245090/> (23 Noviembre 2019).

DELEUZE Gilles \& GUATTARI Felix (1980), Capitalisme et schizophrénie, Mille plateaux, Paris: Les éditions de minuit.

DELEUZE Gilles \& PARNET Claire (1996), Dialogues, Paris: Flammarion.

DURAN-MERK Alma (2010), «Representaciones de la experiencia migratoria en la literatura: Los detectives salvajes de Roberto Bolaño», en línea en Proyecto Patrimonio - 2010: <http://

letras.mysite.com/rb221110.html> (10 Diciembre 2019). 
ESPINOSA Patricia (2010), «Notas sobre la poesía cinética. Movimiento y realidad en la poesía de Roberto Bolaño», Quimera Revista de literatura (314), 51-57, Barcelona: Ediciones de intervención cultural S.L.

ESPINOSA Patricia (2003), Territorios en fuga: estudios críticos sobre la obra de Roberto Bolaño, Santiago de Chile: Frasis editores.

FISBACH Erich (2010), «Une lecture de La pista de hielo de Roberto Bolaño», K. Benmiloud et al. (dir.), Les astres noirs de Roberto Bolaño, Bordeaux: Presses universitaires de Bordeaux, 163-172.

GUEVARA Santiago (2013), «Dos notas acerca de la relación entre poesía y prosa en Bolaño», La palabra, 22, Tunja: Editorial LS, 55-66.

HAREL Simon (2005), Les Passages obligés de l'écriture migrante, Montréal: XYZ.

MACAYA Ángeles (2009), «Estética, Política y el posible territorio de la ficción en 2666 de Roberto Bolaño», Revista Hispánica moderna, 62(2), Pennsylvania: University of Pennsylvania press, 125-142. MANZONI Celina et al. (2005), Jornadas de homenaje a Roberto Bolaño (1953-2003): simposio internacional, Barcelona: Casa América a Cataluña.

MANZONI Celina (2002), Roberto Bolaño: La escritura como tauromaquia, Buenos Aires: Corregidor. MONTANÉ Bruno (2010), «La poesía de Roberto Bolaño», Quimera Revista de literatura (314), Barcelona: Ediciones de intervención cultural S.L., 32-34.

MORENO Fernando (2005), Roberto Bolaño: una literatura infinita, Poitiers: Centre de recherches latinoaméricaines.

SÁNCHEZ Alejandro (2012), Por una ética del desorden en América latina, en línea en Scielo: <http:// www.scielo.org.co/scielo.php?script=sci_issuetoc\&pid=0121-755020120002\&lng=es > (16 Octubre 2019).

\section{NOTAS}

1. Bolaño Roberto, La prosa de otoño en Gerona; poema fechado de 1981 y publicado en Tres (Acantilado, 2000). Este verso cierra el poema en mención.

2. Palabras leídas por Roberto Bolaño durante la ceremonia de entrega y recepción del premio Rómulo Gallegos en Caracas, Venezuela, en el año de 1998.

\section{RESÚMENES}

La figura y la obra de Roberto Bolaño (1953-2003) están marcadas de extraterritorialidad. Este descentramiento geográfico/literario le conduce a situarse en un territorio intermedio $\mathrm{y}$, por lo mismo, a producir una obra ambivalente, inestable y vertiginosa impregnada por el nomadismo de los personajes y por la proyección de un marco de valores propio. Este nomadismo literario del autor puede ser estudiado a partir no sólo de la desarticulación del centro enunciativo sino también de la desterritorialización de su obra que produce una narrativa en continuo 
movimiento. Estas variantes adquieren relevancia en el contexto de la obra por cuanto dan cuenta de los valores que guían a los personajes nómadas a la vez que proveen indicios sobre el marco axiológico de éstos y de la obra misma. Estudiaremos la manera como Bolaño se sirve de recursos narratológicos; intertextualidad, extraterritorialidad y desterritorialización para postular una serie de valores que caracterizan su obra y que se proyectan como las bases de un ethos propio al autor.

La figure et l'œuvre de Roberto Bolaño (1953-2003) sont marquées par l'extraterritorialité. Ce décentrement géographique et littéraire l'ont conduit à se positionner dans un territoire intermédiaire et par conséquent à produire une œuvre ambivalente, instable et vertigineuse imprégnée par le nomadisme des personnages et par la projection d'un cadre de valeurs propre. Le nomadisme littéraire de l'auteur peut être abordé par la désarticulation du centre énonciatif mais aussi par la déterritorialisation, produisant une œuvre en mouvement continu. Ces éléments peuvent rendre compte des valeurs qui guident les personnages nomades, au même titre qu'ils fournissent des indices sur leur cadre axiologique et sur celui de l'œuvre. Nous étudierons la manière dont Bolaño se sert des ressources narratologiques; intertextualité, extraterritorialité et déterritorialisation pour proposer une série de valeurs qui distinguent son œuvre et qui constituent les bases de la projection d'un ethos propre à l'auteur.

Roberto Bolaño (1953-2003) managed to make of his image and literary work an extraterritorial space. This geographical and literary decentralization have led him to place himself in an intermediate territory, thus, to create an ambivalent, instable and vertiginous work impregnated with the characters' nomadism and with his own frame of values. Bolaño's nomadism can be analyzed by the disarticulation of the narrative center as well as by the deterritorialization of his works which have produced a moving literature. These items can account for the values which guide the nomadic characters and for the clues that determine their axiological framework. We will study the way Bolaño uses narrative techniques; intertextuality, extraterritoriality and deterritorialization in order to establish a frame of specific values in his literary works in according to a projection of his own ethos.

\section{ÍNDICE}

Palabras claves: Nomadismo, extraterritorialidad, desterritorializar, intertextualidad, axiología

Keywords: Nomadism, extraterritoriality, deterritorialize, intertextuality, axiology

Mots-clés: Nomadisme, extraterritorialité, déterritorialiser, intertextualité, axiologie

\section{AUTOR}

\section{SANTIAGO GUEVARA}

Docteur en littérature hispanoaméricaine, Université de Savoie Mont-Blanc 